\title{
Die Erziehungsmission der Familie: Aktuelle Herausforderungen und neue Konzeptionen
}

\section{The Educational Mission of the Family: Current Challenges and New Concepts}

\begin{abstract}
The family is often identified as the place where the future of society is guaranteed or destroyed. As the current family is obviously shifting in many regards in contemporary society the traditional educational responsibilities of the family are challenged. The educational mission of the family supposes intensive and ongoing work with the parents. What parents experience and learn becomes the living source for the pedagogical journey with their children. The author of this article explores various aspects of the new situation of education within the family in XXI century. He also reconsiders the challenges, concepts and contribution of the family in the educational mission in a contemporary European context.
\end{abstract}

\section{Keywords}

Family, education, civilization, development, human dignity.

Die Familie ist nicht nur die bedeutendste sondern auch die natürlichste Lebensund Erziehungsgemeinschaft. Diese Wahrheit bleibt jedoch, insbesondere in den letzten Jahren, immer häufiger lediglich ein schönes Postulat an die Familie. Zweifellos besteht ein Symptom der modernen Zivilisation darin, dass die 
Familie als Erziehungsgemeinschaft in einer nicht zu unterschätzenden Krise steckt. Diese geht mit Sicherheit vor allem daraus hervor, dass sich die Eltern aktuell etwas zu wenig des Geschenks, aber auch der Herausforderung bewusst sind, die mit Mutter- und Vaterschaft verbunden sind. Zu leicht wird heutzutage vergessen, dass verantwortungsvolle Elternschaft für den Christen den Weg darstellt, die von Gott erhaltene Berufung zu verwirklichen. Hierbei geht es um die Berufung, welche die Quelle des erzieherischen Sendungsauftrags der familiären Gemeinschaft ausmacht. ${ }^{1}$

Darum erscheint es nur zu berechtigt, dass der vorliegende Artikel das Problem der Erziehungsmission, welche die Familie realisiert, und die damit verbundenen aktuellen Herausforderungen aufgreift. Zunächst werden die Herausforderungen der modernen Zivilisation und deren Einfluss auf die Erziehungsfunktion der Familie präsentiert. Der zweite Teil stellt eine neuartige Konzeption der Erziehung im Rahmen der Familie vor, wobei der Schwerpunkt auf die Unterstützung der kindlichen Entwicklung, die Achtung der Würde des Menschen und dessen Fortschritte im geistlich-religiösen Bereich gelegt wird.

\section{Aktuelle Herausforderungen durch die moderne Zivilisation}

Der Mensch verfügt in der heutigen Zeit über ein immenses Maß an Wissen und Technologie. Hierbei genügt es den Blick auf den enormen Fortschritt in der Landwirtschaft, der Biologie, der Medizin, aber auch auf die Anwendung sozialer Formen im Bereich des Schulwesens sowie der gesellschaftlichen und

${ }^{1}$ Siehe auch: J. Stala, Ręce mego ojca i usta mojej matki powiedziały mi najwięcej o Bogu. Biskupa Piotra Bednarczyka ujęcie katechezy rodzinnej, Tarnów 2011; J. Stala, W kierunku integralnej edukacji religijnej w rodzinie. Próba refleksji nad nauczaniem Jana Pawła II w kontekście polskich uwarunkowań, Tarnów 2010; The Contemporary Family: Local and European Perspectives, Hrsg. E. Osewska, J. Stala, Kraków 2015; Religious Education / Catechesis in the Family. A European Perspective, Hrsg. E. Osewska, J. Stala, Warszawa 2010; J. Stala, Familienkatechese in Polen um die Jahrhundertwende. Probleme und Herausforderungen, Tarnów 2008; W poszukiwaniu katechezy rodziców. Studium teoretyczno-empiryczne, Hrsg. J. Stala, E. Osewska, Tarnów 2007; Rodzina. Bezcenny dar i zadanie, Hrsg. J. Stala, E. Osewska, Radom 2006; Dzisiejsze aspiracje katechezy rodzinnej. Problemy i wyzwania, Hrsg. J. Stala, Kielce 2005; J. Stala, Katecheza o małżeństwie i rodzinie w Polsce po Soborze Watykańskim II. Próba oceny, Tarnów 2004. 
ökonomischen Wissenschaften zu richten. Sie alle könnten jedoch, was einerseits offensichtlich erscheint, andrerseits dagegen eher unrealistisch ist, einen Prozess anstoßen, die Industrialisierung und Urbanisierung humanitärer und erfolgreicher auszugestalten, um neue Formen der internationalen Zusammenarbeit zu initiieren. Dabei hat die Familie zweifellos eine grundlegende Rolle zu übernehmen, die sogar für den Menschen, der ein Leben als Single gewählt hat, der existenzielle Horizont verbleibt, denn auf diese Gemeinschaft stützt sich das gesamte Leben der Menschheit. ${ }^{2}$

$\mathrm{Zu}$ Beginn des dritten Jahrtausends dauert jedoch die Unruhe fort, die auf besondere Weise gerade diese Institution betrifft, die für den Menschen eine der bedeutendsten darstellt. Basis für diese Erscheinung ist vor allem eine allgemein um sich greifende Loslösung der Familie und ihrer Funktionen von Gott. Als Konsequenz aus der Negierung Gottes ergeben sich ein immer weiter verbreiteter existenzieller und praktizierter Atheismus sowie eine deutliche Schwächung der religiösen Einflussnahme, die rein auf den privaten Bereich eingeschränkt wird. Dies betrifft sogar Familien, die sich als christlich bezeichnen, in denen aber die Kinder nur noch im Gebet unterwiesen und zur Teilnahme an den Gottesdiensten und den Religionsstunden geschickt werden. Selbst in Familien, die der Religion nicht ablehnend gegenüber stehen, empfindet man kein Bedürfnis nach der Zwiesprache mit Gott und der Vertiefung seines religiösen Wissens. ${ }^{3}$ In der heutigen Zeit lässt sich ein eigenartiges Phänomen beobachten, das der Familie eine ganze Reihe ihrer religiösen und erzieherischen Funktionen entzieht. Die Veränderungen der gesellschaftlichen Situation, in welcher die Familie auf der einen Seite dem Medieneinfluss und der rasanten Entwicklung des Schulwesens begegnet, in welcher sie jedoch auf der anderen Seite einer Kirche gegenüber steht, die um die Reinheit des Kultes und der Richtigkeit der Lehre bemüht ist, all diese Fakten führten dazu, dass die Familie immer weniger zum Ort für Kulthandlungen und die Weitergabe religiöser Inhalte und Werte wurde. Weiterhin lässt sich

${ }^{2}$ Vgl. Gratissimum sane 2; siehe auch: Rodzina dla Europy czy Europa dla rodziny?, Hrsg. W. Korzeniowska, A. Murzyn, H. Lukasova-Kantorkova, Kraków 2006; Rodzina jako wartość w rozwoju człowieka, Hrsg. B. Harwas-Napierała, Poznań 2009; Rodzina we wspótczesności, Hrsg. A. Ładyżyński, Wrocław 2009; Rodzina wobec zagrożeń, Hrsg. M. Duda, Kraków 2008; A. F. Dziuba, Rodzina w dialogu z Bogiem w nauczaniu ojca Świętego Jana Pawła II. Zarys problematyki, Warszawa 2006.

${ }^{3}$ Vgl. Familiaris consortio 36. 
ein Umbruch dahingehend beobachten, dass die Qualifizierung der Eltern, bedingt oder unbedingt, in diesem Bereich deutlich nachlässt. Die Kirche hat die Notwendigkeit erkannt, die Eltern in Verbindung mit der Schule bei der Religionserziehung weitgehend zu ersetzen, wie auch die Eltern selbst damit einverstanden waren und der Kirche mehr Aufgaben übertragen haben, als diese ihnen abnehmen konnte. ${ }^{4}$

Leider kann die Familie bei ihren erzieherischen Funktionen auch nicht auf die Hilfe des Staates zählen, der nur zu häufig vergisst, dass gerade die Familie "die Schule einer reicheren Menschlichkeit" ist. Die nachlassende Qualität der Erziehungsarbeit in der Familie weist in einer Phase der gesellschaftlichen Umgestaltung besondere Charakteristika auf, die beispielsweise mit der Industrialisierung, der Urbanisierung und einer demographischen Explosion einhergehen. Die Krise der heutigen Familie steigert sich noch weiter durch die kaum kontrollierbare Einflussnahme der Massenmedien, die sich sehr stark darauf konzentrieren, die traditionellen Werte zu schwächen oder lächerlich zu machen, dagegen aber Werte zu propagieren, die konträr zur katholischen Weltanschauung stehen. Im Falle einer Gesellschaft, welche die Rolle der Eltern bei der Erziehung zur Liebe negiert und gering schätzt, lässt sich nur schwerlich von deren Weiterentwicklung, höchstens von ihrer Existenz sprechen. ${ }^{6}$

Es ist zu bemerken, dass das Familienleben in allen Bereichen nahezu erzwungenermaßen atheistischer und laizistischer wird. Nicht selten verblasst die eigentliche Mission der Familie sogar vollständig, indem man ihre wahre

${ }^{4}$ Vgl. Jan Paweł II, Rodzice pierwszymi nauczycielami wiary. W czasie Mszy Świętej, podczas której papież udzielit I Komunii świętej, Cardiff, Wielka Brytania, 2 VI 1982, in: Dziecko w nauczaniu Jana Pawła II, Hrsg. J. Żukowicz, Kraków 1985, S. 80-81; D. Baran, Szkoła dla rodziców - trwająca całe życie nauka dialogu z dziećmi, in: Dziecko i rodzina. Społeczne powinności opieki i wychowania, Hrsg. U. Gruca-Miąsik, Rzeszów 2007, S. 202-213; Dziecko i rodzina. Społeczne powinności opieki i wychowania, Hrsg. U. Gruca-Miąsik, Rzeszów 2007.

${ }^{5}$ Familiaris consortio 21; Vgl. Gaudium et spes 52.

${ }^{6} \mathrm{Vgl}$. T. Zbyrad, Miejsce i rola organizacji pozarządowych w instytucjonalnym systemie pomocy rodzinie, in: Rodzina wobec zagrożeń, Hrsg. M. Duda, Kraków 2008, S. 277-287; A. Murzyn, Samotne dzieci w hotelu „Europa”, in: Rodzina dla Europy czy Europa dla rodziny?, Hrsg. W. Korzeniowska, A. Murzyn, H. Lukasova-Kantorkova, Kraków 2006, S. 191-207; M. Biedroń, Realizacja funkcji rodziny w kontekście globalnych przemian socjokulturowych, in: Rodzina we współczesności, Hrsg. A. Ładyżyński, Wrocław 2009, S. 39-57; I. Kubiak, Przekaz Transgeneracyjny w funkcjonowaniu systemu rodzinnego, in: Rodzina we współczesności, Hrsg. A. Ładyżyński, Wrocław 2009, S. 69-78. 
Bestimmung verneint, dass sie nämlich vor allem die Gemeinschaft ist, die Leben schenkt. Ihre Unauflöslichkeit und Fortdauer verfällt zugunsten von Ehe auf Probe, Scheidung und freier Bindung. Durch die rechtliche Gleichstellung von homosexuellen Partnerschaften mit der konstanten Gemeinschaft von Mann und Frau wird ihr tatsächliches Wesen schließlich komplett negiert. ${ }^{7}$ Die Krise der Familie und die abnehmende Wertschätzung ihrer Rolle reichen heute häufig bis in die fundamentalsten Angelegenheiten wie etwa das Verständnis des Familienbegriffs selbst hinein. Hier genügt es an die Probleme zu erinnern, die mit der Definition des Terminus „Familie” einhergehen, den man im internationalen öffentlichen Recht anerkennen würde. ${ }^{8}$

Darüber hinaus kann man bereits die allgemein verbreitete wie auch traurige Feststellung treffen, dass die moderne Zivilisation eine Zivilisation des Todes ist, die das menschliche Leben nicht selten unterbindet, wenn man an die in den Parlamenten übliche Gesetzgebung zum Recht auf Abtreibung empfangener Kinder denkt. ${ }^{9}$

Auf der anderen Seite erlebt die Familie immer häufiger schon in ihrem eigenen Inneren eine Krise, welche die Realisierung ihrer Erziehungsfunktion erschwert. Hier ist vor allem die These anzuführen, dass der Prozess der Säkularisierung aktuell konsequent voran schreitet. Insbesondere in der Zone der westlichen Länder setzt sich der zunächst spontane Prozess weiter fort, in dessen Verlauf die moderne Familie ihren religiösen Charakter mehr und mehr verliert. ${ }^{10}$ Die Wahrnehmung des „familiären Heims” als einen Ort, wo sich das Familienleben stabilisiert, wo sich familiäre Tradition und Kultur ausprägen, wo das Haus gewissermaßen geheiligt wird, nimmt verstärkt ab. Die Säkularisierung der Familie wird dahingehend zu einem Fakt, dass sie vor allem im geistlichen Bereich und im religiösen Leben des Menschen immer weniger Bedeutung einnimmt. Dies wirkte sich sehr negativ auf die Fähigkeit der Familie aus, ihre grundlegenden Funktionen zu erfüllen, Rituale

7 Vgl. S. Stefanek, Sytuacja współczesnej rodziny polskiej - widzenie pastoralne, in: Nadzieje i zagrożenia współczesnej rodziny, Kraków 1994, S. 29.

${ }^{8}$ Vgl. Rodzina na przełomie wieków, Hrsg. K. Majdański, Łomianki 2000, S. 256-257.

9 Vgl. W. Majkowski, Społeczny kontekst i społeczne skutki przerywania ciąży, in: Nadzieje zagrożenia wspótczesnej rodziny, Kraków 1994, S. 195; S. Stefanek, Sytuacja współczesnej rodziny polskiej - widzenie pastoralne, in: Nadzieje i zagrożenia współczesnej rodziny, Kraków 1994, S. 27.

${ }^{10}$ Vgl. J. Bolero, Nieregularne sytuacje rodziny wyzwaniem dla współczesnej teologii moralnej, in: Nadzieje i zagrożenia współczesnej rodziny, Kraków 1995, S. 137-138. 
ekklesialen Wesens zu praktizieren und ihre bedeutende Rolle in der Kirche einzunehmen. ${ }^{11}$

In der heutigen Welt sehen wir eine fortschreitende Krise dabei, in der elterlichen Berufung konstant und dauerhaft treu zu bleiben. Diese Krise drückt sich vor allem darin aus, dass die Eltern häufig die Erziehung ihrer Kinder überhaupt nicht oder nur in geringem Ausmaß aufnehmen, zeitweise steht das Kind sogar in der Konkurrenz zu anderen Dingen. ${ }^{12}$ Leider vergessen viele Eltern, dass die Zusammenarbeit mit Gott bei der Weitergabe des Lebens nicht mit Empfängnis und Geburt des Kindes endet sondern dass der Prozess der Erziehung kontinuierlich weiter geht. Sie verlieren nicht selten, und das ist besonders gefahrvoll, das Gefühl ihrer eigenen Verantwortung für die religiöse Erziehung ihrer Kinder. Das zeigt sich besonders in jenen Familien, wo Erfolge in der Arbeit, in der Schule und im Sport mehr beachtet und wertgeschätzt werden als religiöse Angelegenheiten und Erfahrungen. ${ }^{13}$

${ }^{11}$ Vgl. Rodzina we współczesności, Hrsg. A. Ładyżyński, Wrocław 2009; Wychowanie a wyzwania ponowoczesności, Hrsg. E. Osewska, Warszawa 2011; J. Stala, Katechese im Zeitalter der Postmoderne. „Grundsatzprogramm für die Katechese der Kirche in Polen“ aus dem Jahr 2010, „Bogoslovni vestnik“ 74 (2014) Nr 1, S. 107-117; J. Stala, Richtungsweisende Merkmale zur religiösen Erziehung und Bildung im Lehrwerk von Papst Johannes Paul II., „Bogoslovska Smotra“ (2014) Nr 1, S. 137-148; J. Stala, Den Jungen Menschen auf den Etappen Seines Lebenswegs Begleiten. Wesentliche Elemente der Jugendkatechese Johannes Pauls II., „Angelicum“ 90 (2013), S. 945-960.

${ }^{12} \mathrm{Vgl}$. Rodzina -wświetle zagrożeń realizacji dotychczasowych funkcji. Szkice monograficzne, Hrsg. W. Korzeniowska, A. Murzyn, U. Szuścik, Katowice 2007; E. Osewska, To Educate in a Diversified Europe, „The Person and the Challenges“ 1 (2011) Nr 1, S. 71-88; H. Lombaerts, E. Osewska, The Modern Christian Family as a First Setting for Religious and Moral education?, in: Religious Education/Catechesis in the Family: A European Perspective, Hrsg. E. Osewska, J. Stala, Warszawa 2010, S. 11-25; E. Osewska, Religious Education from the Perspective of Central and Eastern Europe, in: Toward Mutual Groud. Pluralism, Religious Education and Diversity in Irish Schools, Hrsg. G. Byrne, P. Kieran, Dublin 2013, S. 133-143.

${ }^{13}$ Die Familie ist nicht nur die wichtigste, sondern gleichzeitig auch die natürlichste Lebensund Erziehungsgemeinschaft für den Menschen. Vor allem in den letzten Jahren verbleibt von dieser Wahrheit jedoch immer häufiger lediglich ein schönes Postulat an die Familie. Zweifellos ist es heute für die Gesellschaft symptomatisch, dass sich die Familie als Erziehungsgemeinschaft in einer schwerwiegenden Krise befindet. Dies ist mit Sicherheit vor allem eine Folge dessen, dass bei vielen Eltern derzeit das Bewusstsein dafür nur schwach ausgeprägt ist, welches Geschenk Mutter- und Vaterschaft darstellen, aber welche Herausforderungen damit auch verbunden sind. Unterdessen darf nicht vergessen werden, dass gerade Mutter- und Vaterschaft für den Christen der Weg sind, auf dem die von Gott erhaltene Berufung realisiert werden kann, die Berufung, die im Zentrum der erzieherischen Sendung der Familiengemeinschaft 


\section{Auf dem Weg zu einer neuartigen Konzeption für die Erziehung in der Familie}

Die Erziehung ist eine der wichtigsten Aufgaben, die sich Einzelpersonen, Familien und schließlich der gesamten Gesellschaft stellt. Denn jeder Mensch kann momentan Situationen, Ereignisse und Einstellungen beobachten, die davon zeugen, dass das Problem der Erziehung und der Entwicklung entsprechender Konzeptionen eine immense Herausforderung für die Menschheit darstellen. Obwohl in der heutigen Zeit viel über Erziehung gesprochen wird und in einigen Gesellschaften bereits deutlich mehr in die Erziehungsarbeit investiert wird, ist der Effekt aller Bemühungen noch nicht zufriedenstellend. Dies ist leider zu bemerken, obgleich das Kind vom frühesten Vorschulalter an in die erzieherische Obhut unterschiedlicher Arten von Lehrern, Pädagogen, Trainern oder sogar Psychologen gegeben wird. In Verbindung damit werden nun einige wegweisende und wesentliche Aspekte aufgezeigt, die bei der Realisierung dieser neuen Konzeption für die Erziehung zu beachten sind: die Unterstützung der kindlichen Entwicklung, die Würde des Menschen und dessen Fortschritte im geistlich-religiösen Bereich.

\subsection{Die Unterstützung der kindlichen Entwicklung}

Gerade in der modernen Zeit braucht der Mensch nicht mehr Erziehung sondern bessere Erziehung, er benötigt eine klar definierte Erziehungskonzeption, die auf dem entsprechenden Menschenbild basiert. Notwendig ist eine Erziehung, die sich auf einen wahrhaften, christlichen Humanismus stützt. Diese Vision hat eigene, ernste Implikationen auch dann, wenn ihre Grundsätze und Konsequenzen nicht immer expressis verbis ausgedrückt werden. Dies ist heute mit besonderer Deutlichkeit in einem oft sogenannten antipädagogischen Erziehungsstil wahrzunehmen, für den jegliche erzieherische Einflussnahme im Grunde als großer Betrug betrachtet wird, der den jungen Menschen die ihnen zustehenden Rechte nimmt. Denn nach Meinung der Antipädagogen verdeckt jedes erzieherische Handeln lediglich die Tatsache, dass die Zöglinge zu Objekten werden, die wie Marionetten von außen in die erwünschte Richtung gelenkt werden. Für die Antipädagogik muss der Erzieher eigentlich so lange

steht. Vgl. J. Stala, Wyzwania stojące przed rodzina realizacji misji wychowawczej, „Polonia sacra" 13 (2009) Nr 25, S. 159-169. 
warten, bis der Zögling selbst um Hilfe bittet. Der Erzieher kann also nicht auf die unbewussten Bedürfnisse des Kindes eingehen, er darf keinerlei Maßnahmen ergreifen, um dieses zur Aufnahme bestimmter Handlungen zu ermuntern, wie etwa zum Lernen. Wenn man diesen Gedanken konsequent zu Ende führt, dann soll der Erzieher einzig auf die Bitten und Signale antworten, die wörtlich und direkt an ihn gerichtet werden, er soll die Entwicklung lediglich - überwiegend beobachtend - begleiten. ${ }^{14}$

Der Begriff von der „Unterstützung der Entwicklung” ist wenig scharf abgegrenzt, was erzieherische Initiativen tatsächlich auch durchkreuzen kann. Denn Entwicklung impliziert eine dynamische Auffassung des Menschen, die Antipädagogik dagegen sieht ihn eher statisch - wichtig ist nur das, was der Zögling „hier und heute” will, eine langfristige Perspektive wird ihm vollkommen abgesprochen.

Wenn sich die Familiengemeinschaft entwickelt, wenn sie also den Grundsatz von der Unterstützung der kindlichen Entwicklung realisiert und die personalistische Norm zum Postulat wird, nämlich die Person für sich selbst anzunehmen, dann wird sie zu einer erwünschten, positiven Erziehungsumgebung, da sie die spezifischen Rahmenbedingungen garantiert, dass sich das subjektive „Ich” aller Mitglieder der Familie im gemeinsamen „Wir” verwirklichen kann. In einer so funktionierenden familiären Gemeinschaft lernt das Kind, nicht nur auf das eigene sondern auch auf das gemeinschaftliche Wohlergehen zu blicken und sich darin selbst zu entdecken - sich also mit der eigenen Unterstützung und der Hilfe der anderen seine persönliche Identität selbst auszubilden. ${ }^{15}$

${ }^{14}$ Vgl. Wychowanie rodzinne $w$ teorii i praktyce. Rozwój pedagogicznej orientacji familiologicznej, Hrsg. A. W. Janke, Toruń 2008; Doświadczenie wartości samego siebie w procesach edukacyjnych, Hrsg. A. M. Tchorzewski, Bydgoszcz 1997, S. 48.

15 Vgl. J. Stala, E. Osewska, Anders erziehen in Polen. Der Erziehungs- und Bildungsbegriff im Kontext eines sich ständig verändernden Europas des XXI. Jahrhunderts, Tarnów 2009; The Contemporary Family: Local and European Perspectives, Hrsg. E. Osewska, J. Stala, Kraków 2015; Religious Education / Catechesis in the Family. A European Perspective, Hrsg. E. Osewska, J. Stala, Warszawa 2010; Nauki o rodzinie w stużbie rodziny, Hrsg. J. Stala, Kraków 2014; Rodzina - w świetle zagrożeń realizacji dotychczasowych funkcji. Szkice monograficzne, Hrsg. W. Korzeniowska, A. Murzyn, U. Szuścik, Katowice 2007; Wychowanie rodzinne w teorii i praktyce. Rozwój pedagogicznej orientacji familiologicznej, Hrsg. A. W. Janke, Toruń 2008. 


\subsection{Die Würde des Menschen}

Obwohl der Mensch ein Wesen ist, das über nahezu uneingeschränkte kognitive Kraft verfügt, kann er in seinem eigenen spezifischen Leben Fortschritte in intellektueller und sittlicher Hinsicht nur dann erzielen, wenn er von kollektiven Erfahrungen unterstützt wird, die von den vorherigen Generationen gesammelt und bewahrt worden sind. Er braucht die Erziehung also notwendigerweise. Bei der Aufnahme dieser großen Aufgabe muss jedoch der Kontext der aktuellen Welt einbezogen werden, in dem sich das Bewusstsein für die persönliche Würde jedes menschlichen Wesens - zumindest per Dekret - weiter verstärkt. $\mathrm{Zu}$ Beginn des dritten Jahrtausends achtet die Menschheit immer mehr auf die Würde des Menschen. Er wird weniger als „Sache” oder „Objekt” betrachtet, derer man sich bedienen kann, sondern ausschließlich als „Subjekt”, das über Gewissen und Freiheit verfügt, das also zu einem verantwortungsvollen Leben in der Gesellschaft aufgefordert ist. ${ }^{16}$

Angesichts einer Gesellschaft, in welcher die einzelne Person überaus gefährdet ist, in der großen Masse unterzugehen und folglich nahezu entmenschlicht zu werden, soll die Erziehung zu einer starken Kraft werden, um den Menschen aus der Anonymität zu ziehen, um in ihm das Bewusstsein für die Würde der eigenen Person aufrecht zu erhalten und um ihn mit der Sehnsucht nach einer tieferen Menschlichkeit zu bereichern. Dies ist besonders wesentlich in der modernen Zivilisation, wo es häufig zu Situationen kommt, in denen wir dem anderen Menschen nicht mehr begegnen sondern in der anonymen Einsamkeit verbleiben, in denen unsere gegenseitigen Beziehungen nur noch selten auf dem zwischenmenschlichen Dialog basieren. Heutzutage ist aber dieser zwischenmenschliche Dialog, gestützt auf die wahrhaft personalistischen Werte, gerade im Erziehungsprozess von erheblicher Bedeutung. Denn der Mensch sucht ein Gegenüber, dem er vertrauen und dessen Erziehungsarbeit er akzeptieren kann.

${ }^{16}$ Vgl. Christifideles laici 5; S. Pyszka, Godność osoby ludzkiej jako podstawa nauczania społecznego Jana Pawła II, in: Testament społeczny Jana Pawła II, Hrsg. J. Kupny, M. Łuczak, Katowice 2006, S. 11-36; J. Stala, Die Freiheit - das besondere Kennzeichen einer modernen Jugenderziehung, „The Person and the Challenges” 3 (2013) Nr 2, S. 193-207; J. Stala, Der Mensch als Person: Die bestimmende Grundlage für Johannes Paul II. in seinem Bild von der Familie, „The Person and the Challenges” 2 (2012) Nr 2, S. 41-59; J. Stala, Die Transzendenz als bestimmendes Merkmal der Person in der Anthropologie und der Pädagogik Johannes Pauls II., „The Person and the Challenges” 2 (2012) Nr 1, S. 61-75. 
Folglich ist die Erziehung ein Handeln, das so personalistisch wie nur möglich ist. Man kann ja nur eine Person erziehen, ein Tier dagegen lässt sich lediglich dressieren. Die Erziehung baut im Menschen das auf, was wirklich „menschlich” ist, aber der wichtigste Bereich des „wirklich Menschlichen” im Zögling ist dessen innere Freiheit. Deshalb soll der Erziehungsprozess auf die Befreiung der Person durch Wissen und Kompetenz, durch freien Willen und Liebe abzielen. Aus diesem Grund muss die Erziehung ein Dialog von Personen sein. ${ }^{17}$ Also stellt die integrale Konzeption des Menschen als Person ein unbedingtes und unerlässliches Element für den Erziehungserfolg dar. Der große Disput über den Menschen ist nämlich, auch in Polen, nicht zusammen mit dem Niedergang der marxistischen Ideologie vollständig beendet worden. Die Debatte dauert fort, in gewisser Hinsicht hat sie sich sogar intensiviert. Die Formen, den Menschen als Person sowie den Wert des menschlichen Lebens zu degradieren, werden weiterhin auf sehr subtile Weise angewendet und sind daher umso gefährlicher. ${ }^{18}$

Die Überzeugung, dass das Kind über eigene Schöpfungskraft verfügt, die ihm bereits durch seine Natur als Person einbeschrieben ist, reicht bis in die Grundlagen der Konzeption, das Kind in der familiären Erziehung als Subjekt zu behandeln. Die Respektierung dieser fundamentalen Tatsache stellt eine unerlässliche Bedingung für die mannigfaltige und harmonische Entwicklung des Kindes dar, die sich ihrem Wesen nach darauf verlassen wird, dass die potenziellen kindlichen Möglichkeiten stets aktualisiert werden. Dies bedeutet jedoch keinesfalls, dass sich die Eltern in ihrer Erziehungsarbeit eher gleichgültig oder passiv verhalten dürfen. Ihre Rolle kann man als pädagogische Assekuranz verstehen, die das Kind unterstützen und positiv stimulieren wird, damit dieses den subjektiven Charakter seiner eigenen Aktivität ausformen kann.

\subsection{Der geistlich-religiöse Fortschritt}

Das übergeordnete Ziel der Erziehung darf jedoch nicht nur auf die Entwicklung des Menschen als Person in der gesellschaftlichen Dimension ausgerichtet

17 Einer der Faktoren, die zum Niedergang der modernen Erziehung beitragen, ist gerade die naturalistische und materialistische Konzeption des Menschen, die den einzigen Ort seines Daseins und seiner Bestimmung im weltlichen Bereich sieht.

${ }^{18}$ Vgl. Jan Paweł II, Wokół Uniwersytetu Jagiellońskiego jednocza się wszystkie uczelnie Polski, Spotkanie z rektorami wyższych uczelni w Polsce z okazji 600-lecia Wydziału Teologicznego Uniwersytetu Jagiellońskiego, Kraków, 8 czerwca 1997, in: Uniwersytety w nauczaniu Jana Pawła II, t. II (1989-1999), Warszawa 2000, S. 251. 
sein, was überaus pragmatisch wäre, sondern soll vor allem den geistlichreligiösen Fortschritt im persönlichen Leben des Menschen anstreben. Eine im ganzheitlichen Sinn verstandene Erziehung muss gleichzeitig das Verständnis für wie den Wunsch nach individueller Vollkommenheit aufbauen. Sie hat sich selbst die Aufgabe zu stellen, die menschliche Persönlichkeit auf ihr letztendliches Ziel hin auszugestalten. In der modernen Erziehung wird häufig vergessen, dass der Mensch nicht lediglich „ist”, sondern immerwährend „bleibt”. Wer jedoch sein Leben nach einem anerkannten Wertesystem ausrichtet und sich daran hält, wird in den Grenzen seines Gewissens frei. Unterdessen wird die heutige Jugend von lautstarken und untereinander rivalisierenden Forderungen in alle möglichen Richtungen getrieben, welche die Aufmerksamkeit auf sich ziehen und sie zum Gehorsam verpflichten wollen. ${ }^{19}$ Darum soll der Schlüssel für den Erfolg der erzieherischen Anstrengungen darin liegen, die Wahrheit zu suchen und das größte Gut - Gott - anzustreben. Dies kann nur gelingen, wenn der Mensch in der Welt den exakt für ihn passenden Platz findet.

Die religiöse Entwicklung des Menschen beginnt mit dem ersten Moment seiner Existenz. Da bereits das kleine Kind das Zeugnis des Gebets braucht, ist es gut, wenn die Eltern von seiner Geburt an am Bett des Säuglings beten. Mit der Zeit wird es dann damit anfangen, ihre Bewegungen nachzuahmen, ihre Worte zu wiederholen und selbst kleine Gebete zu formulieren. Es ist vielleicht vermessen, hier von den „familiären Wurzeln des Glaubens” zu sprechen, denn der Glauben ist im Grunde der Sache ja eine Gnade, ein Geschenk und eine Aufforderung, eingebettet in die Liebe Gottes, der sich auf diese Weise dem konkreten Menschen anbietet. Ein Zeichen dieser ersten und besonderen Gabe besteht darin, dass der konkrete Mensch konkrete Eltern und ein konkretes Familienheim als Vorsehungsort bekommt, an dem dieses Geschenk Früchte tragen kann. Anders ausgedrückt: Hier soll der Mensch durch die Erziehung darauf vorbereitet werden, Gott auf seine Gabe zu antworten. Die Idee Gottes erschafft sich nach dem Vorbild der Eltern, die bei den Eltern wahrnehmbaren

19 Vgl. Jan Paweł II, Wychowawcy wypetniaja jedno z najważniejszych zadań Kościoła, Spotkanie z nauczycielami i wychowawcami, St. John's (Kanada), 12 września 1984, in: Wychowanie w nauczaniu Jana Pawła II (1978-1999), Warszawa 2000, S. 257; K. Korab, Personalizm a wychowanie, in: Jak wychowywać, Poznań 1999, S. 9; Rodzina w kontekście współczesnych problemów wychowania, Hrsg. B. Muchacka, Kraków 2008; E. Osewska, Religious Education from the Perspective of Central and Eastern Europe, in: Toward Mutual Groud. Pluralism, Religious Education and Diversity in Irish Schools, Hrsg. G. Byrne, P. Kieran, Dublin 2013, S. 133-143; E. Osewska, Education and Internet Challenges, in: Education and Creativity, Hrsg. E. Osewska, Warszawa 2014, S. 43-56. 
Eigenschaften werden im Folgenden auf die personale Konzeption Gottes übertragen. Alles, was das Kind in der Familie erlebt, wirkt sich auf sein Gottesbild aus. ${ }^{20}$ Ohne die Familienkatechese kann die religiöse Bildung des Kindes nicht existieren.

Damit die religiöse Entwicklung des Kindes authentisch ist, muss es die in der Familie anerkannten Dogmen des Glaubens aus freier und bewusster Entscheidung auch für sich annehmen. Wenn dem Kind eine bestimmte Orientierung oder gewisse religiöse Praktiken aufgedrängt werden, dann führt dies im Allgemeinen zum umgekehrten und nicht zum angestrebten Ergebnis. Im Kind können sich dann Aufruhr und Widerstand regen. Die einzige Chance, das Kind positiv an die in der Familie anerkannten Glaubenswahrheiten heran zu führen, besteht darin, ihm in dieser Hinsicht Freiheit und die Möglichkeit zur eigenen Entscheidung zu gewähren, es aber gleichzeitig auf dem selbst gewählten Weg zu begleiten. Dies entbindet die Eltern jedoch keinesfalls von ihrem Recht, das Kind religiös zu erziehen. Vielmehr wird hier darauf verwiesen, dass man das Kind als Subjekt zu betrachten hat, damit dieses seine religiöse Überzeugung aus dem eigenen Ich heraus ausbilden kann. Dann wird die Rolle der Eltern bei der religiösen Entwicklung des Kindes zu einer verantwortungsvollen Aufgabe, die dem Kind die religiösen Werte durch das persönliche Lebensbeispiel vermittelt. Gerade die Authentizität seines mit eigenen Worten ausgedrückten Glaubens verleiht diesen Aussagen besondere Glaubwürdigkeit. Die häusliche Katechese vollzieht sich so auf ganz natürliche Art und Weise, also im Rahmen der alltäglichen Kontakte zwischen Eltern und Kind. Da sich die religiöse Überzeugung der Eltern durch die zwischenmenschlichen Beziehungen innerhalb der Familie aktualisiert, ist ihre Authentizität von fundamentaler Bedeutung. ${ }^{21}$

${ }^{20}$ Vgl. Rodzina i edukacja w zmaganiu o przyszłość Europy, Hrsg. E. Osewska, Tarnów 2016; Focus on Family and Education, Hrsg. E. Osewska, Split 2016; Strengthening Families, Hrsg. J. Stala, Kraków 2017; J. Wilk, Pedagogika rodziny. Zagadnienia wybrane, Lublin 2002, S. 127-128; E. Osewska, Wychowanie modlitewne dzieci w wieku przedszkolnym, in: Wychowanie dzieci w wieku przedszkolnym, Hrsg. E. Osewska, J. Stala, Tarnów 2005, S. 249-274.

${ }^{21}$ Vgl. E. Osewska, Edukacja religijna w szkole katolickiej w Anglii i Walii w świetle „Living and Sharing Our Faith. A National Project of Catechesis and Religious Education", Tarnów 2008; H. Lombaerts, E. Osewska, Family Catechesis/ Religious Education in $21^{\text {st }}$ century Europe, in: Religious Education/Catechesis in the Family: A European Perspective, Hrsg. E. Osewska, J. Stala, Warszawa 2010, S. 27-47; E. Osewska, Wspólnota rodzinna w służbie wychowania, „Family Forum” 4 (2014), S. 125-139; J. Stala, Katecheza rodzinna w nauczaniu Kościoła od Soboru Watykańskiego II, Tarnów 2009; E. Osewska, J. Stala, W kierunku katechezy rodzinnej, 
Die moderne Familie, die unter dem Einfluss der immensen gesellschaftlichen Veränderungen von Grund auf umgestaltet wird, trifft zweifellos bei der Erfüllung ihrer Erziehungsmission auf eine wachsende Zahl von externen Problemen und Schwierigkeiten. Eine Hauptursache für die Krise der Familie besteht daneben auch in einer unzureichenden pädagogischen Vorbereitung der Eltern. Der erörterte Problemkreis veranlasst dazu, gerade heute vermehrt an die bedingungslose Priorität zu erinnern, dass die Erziehung des jungen Menschen eben vor allem in der Familie stattfinden soll. Als natürliche Erziehungsgemeinschaft verfügt die Familie über vortreffliche und nahezu unermessliche Möglichkeiten, deshalb muss auf diesen unschätzbaren Reichtum und seine große Bedeutung fortwährend hingewiesen werden.

\section{Bibliography}

Doświadczenie wartości samego siebie w procesach edukacyjnych, Hrsg. A. M. Tchorzewski, Bydgoszcz 1997.

Dziecko i rodzina. Społeczne powinności opieki i wychowania, Hrsg. U. Gruca-Miąsik, Rzeszów 2007.

Dzisiejsze aspiracje katechezy rodzinnej. Problemy i wyzwania, Hrsg. J. Stala, Kielce 2005.

Dziuba A. F., Rodzina w dialogu z Bogiem w nauczaniu ojca Świętego Jana Pawła II. Zarys problematyki, Warszawa 2006.

Education and Creativity, Hrsg. E. Osewska, Warszawa 2014.

Focus on Family and Education, Hrsg. E. Osewska, Split 2016.

Nadzieje i zagrożenia współczesnej rodziny, Kraków 1994.

Nauki o rodzinie w stużbie rodziny, Hrsg. J. Stala, Kraków 2014.

Osewska E., Edukacja religijna w szkole katolickiej w Anglii $i$ Walii w świetle „Living and Sharing Our Faith. A National Project of Catechesis and Religious Education", Tarnów 2008.

Osewska E., Religious Education from the Perspective of Central and Eastern Europe, in: Toward Mutual Groud. Pluralism, Religious Education and Diversity in Irish Schools, Hrsg. G. Byrne, P. Kieran, Dublin 2013, S. 133-143.

Osewska E., Stala J., W kierunku katechezy rodzinnej, Kielce 2003.

Kielce 2003; J. Stala, Tradycja katechezy rodzinnej w diecezji tarnowskiej, Tarnów 1999; J. Stala, Podstawy teologiczno-antropologiczne katechezy rodzinnej. Na podstawie dokumentów Magisterium soborowego i posoborowego, Tarnów 1998. 
Osewska E., To Educate in a Diversified Europe, „The Person and the Challenges“ 1 (2011) Nr 1, S. 71-88.

Osewska E., Wspólnota rodzinna w służbie wychowania, „Family Forum” 4 (2014), S. 125-139.

Religious Education / Catechesis in the Family. A European Perspective, Hrsg. E. Osewska, J. Stala, Warszawa 2010.

Rodzina - w świetle zagrożeń realizacji dotychczasowych funkcji. Szkice monograficzne, Hrsg. W. Korzeniowska, A. Murzyn, U. Szuścik, Katowice 2007.

Rodzina - w świetle zagrożeń realizacji dotychczasowych funkcji. Szkice monograficzne, Hrsg. W. Korzeniowska, A. Murzyn, U. Szuścik, Katowice 2007.

Rodzina dla Europy czy Europa dla rodziny?, Hrsg. W. Korzeniowska, A. Murzyn, H. Lukasova-Kantorkova, Kraków 2006.

Rodzina i edukacja w zmaganiu o przyszłość Europy, Hrsg. E. Osewska, Tarnów 2016.

Rodzina jako wartość w rozwoju człowieka, Hrsg. B. Harwas-Napierała, Poznań 2009.

Rodzina na przełomie wieków, Hrsg. K. Majdański, Łomianki 2000.

Rodzina w kontekście współczesnych problemów wychowania, Hrsg. B. Muchacka, Kraków 2008.

Rodzina we współczesności, Hrsg. A. Ładyżyński, Wrocław 2009.

Rodzina wobec zagrożeń, Hrsg. M. Duda, Kraków 2008.

Rodzina. Bezcenny dar i zadanie, Hrsg. J. Stala, E. Osewska, Radom 2006.

Stala J., Den Jungen Menschen auf den Etappen Seines Lebenswegs Begleiten. Wesentliche Elemente der Jugendkatechese Johannes Pauls II., „Angelicum“90 (2013), S. 945-960.

Stala J., Der Mensch als Person: Die bestimmende Grundlage für Johannes Paul II. in seinem Bild von der Familie, „The Person and the Challenges” 2 (2012) Nr 2, S. 41-59.

Stala J., Die Freiheit - das besondere Kennzeichen einer modernen Jugenderziehung, „The Person and the Challenges" 3 (2013) Nr 2, S. 193-207.

Stala J., Die Transzendenz als bestimmendes Merkmal der Person in der Anthropologie und der Pädagogik Johannes Pauls II., "The Person and the Challenges” 2 (2012) Nr 1, S. 61-75.

Stala J., Familienkatechese in Polen um die Jahrhundertwende. Probleme und Herausforderungen, Tarnów 2008.

Stala J., Katechese im Zeitalter der Postmoderne. „Grundsatzprogramm für die Katechese der Kirche in Polen“aus dem Jahr 2010, „Bogoslovni vestnik“ 74 (2014) Nr 1, S. 107-117.

Stala J., Katecheza o matżeństwie i rodzinie w Polsce po Soborze Watykańskim II. Próba oceny, Tarnów 2004.

Stala J., Katecheza rodzinna w nauczaniu Kościoła od Soboru Watykańskiego II, Tarnów 2009.

Stala J., Osewska E., Anders erziehen in Polen. Der Erziehungs- und Bildungsbegriff im Kontext eines sich ständig verändernden Europas des XXI. Jahrhunderts, Tarnów 2009. 
Stala J., Podstawy teologiczno-antropologiczne katechezy rodzinnej. Na podstawie dokumentów Magisterium soborowego i posoborowego, Tarnów 1998.

Stala J., Ręce mego ojca i usta mojej matki powiedziały mi najwięcej o Bogu. Biskupa Piotra Bednarczyka ujęcie katechezy rodzinnej, Tarnów 2011.

Stala J., Richtungsweisende Merkmale zur religiösen Erziehung und Bildung im Lehrwerk von Papst Johannes Paul II., „Bogoslovska Smotra“" (2014) Nr 1, S. 137-148.

Stala J., Tradycja katechezy rodzinnej w diecezji tarnowskiej, Tarnów 1999.

Stala J., W kierunku integralnej edukacji religijnej w rodzinie. Próba refleksji nad nauczaniem Jana Pawła II w kontekście polskich uwarunkowań, Tarnów 2010.

Stala J., Wyzwania stojace przed rodzina realizacji misji wychowawczej, „Polonia sacra” 13 (2009) Nr 25, S. 159-169.

Strengthening Families, Hrsg. J. Stala, Kraków 2017.

Testament społeczny Jana Pawła II, Hrsg. J. Kupny, M. Łuczak, Katowice 2006.

The Contemporary Family: Local and European Perspectives, Hrsg. E. Osewska, J. Stala, Kraków 2015.

W poszukiwaniu katechezy rodziców. Studium teoretyczno-empiryczne, Hrsg. J. Stala, E. Osewska, Tarnów 2007.

Wilk J., Pedagogika rodziny. Zagadnienia wybrane, Lublin 2002.

Wychowanie a wyzwania ponowoczesności, Hrsg. E. Osewska, Warszawa 2011.

Wychowanie dzieci w wieku przedszkolnym, Hrsg. E. Osewska, J. Stala, Tarnów 2005.

Wychowanie rodzinne w teorii i praktyce. Rozwój pedagogicznej orientacji familiologicznej, Hrsg. A. W. Janke, Toruń 2008.

Wychowanie w nauczaniu Jana Pawła II (1978-1999), Warszawa 2000. 